\title{
Design Analysis and Fabrication of Solar Vapour Absorption
}

\author{
S. Neelophar Begum, CH. Ravi kiran, K. Vasundara
}

\begin{abstract}
Solar energy is one of the greenest sources of electricity and the idea of using it to power transportation is not new. In this work, parabolic dish is used to collect the solar irradiation, instead of Photo voltaic cells (PVC). This radiation is focused on to a point, where the water is heated to the required temperature and this heat energy is transferred to vapour absorption unit through the heat exchanger. In vapour absorption system (Three fluid systems) consists of a combination of three fluids ammonia and water and hydrogen. These fluids complete the vapour absorption cycle and provide the sufficient cooling. The experiments are conducted on the Solar Vapour absorption unit from 9:00A.M to 5:00P.M. For two days. Temperature readings of generator, Evaporator are taken on an hourly basis and C.O.P of the system at the minimum evaporator temperature is calculated. The system had attained a minimum evaporator temperature of $23^{\circ} \mathrm{C}$ at its peak generator temperature of $92^{\circ} \mathrm{C}$.
\end{abstract}

Index Terms: Photo-Voltaic Cells, Temperature, Three-Fluid System, Vapour Absorption System.

\section{INTRODUCTION}

Solar energy is abundantly available and inexhaustible source of energy. The earth receives energy from sun approximately 1.8 1011 MW which is greater than our solar energy commercial usage rate [1]. Meanwhile solar energy is supply continuously for all present and future energy needs. Hence, solar energy is the most promising unconventional energy sources. Solar energy has many factors in its favor with respect to availability, green environment and renewability [2-4]. This work involves operate refrigeration system with the use of solar energy. Now a day's refrigerator has many domestic applications with great practical relevance. The vapour absorption refrigerator cycle invented in the $1920 \mathrm{~s}$ is based on ammonia (refrigerant) and water (absorbent) as the working fluids together with hydrogen as an auxiliary inert gas [5]. Since there are no moving parts in the unit, the vapour absorption refrigerator system is both quiet and reliable. This system can be adopt in hotel rooms and offices. The vapour absorption refrigerator work under the principle of refrigerating machine mono pressure introduced by PLATERN and MUNTER. In this system three operating fluids are used such as water as absorbent, ammonia as refrigerant and hydrogen as inert gas in order to maintain the total pressure constant [6-7].

Revised Manuscript Received on July 22, 2019.

S. Neelophar Begum, Department of Mechanical Engineering, MLR Institute of Technology, Hyderabad, India.

CH. Ravi kiran, Department of Mechanical Engineering, MLR Institute of Technology, Hyderabad, India

K. Vasundara, Department of Mechanical Engineering, MLR Institute of Technology, Hyderabad, India

\section{LITERATURE SURVEY}

Subhadip Roy [8] et al. has done experiments on R134a-DMAC vapour absorption refrigeration system. To attain low cooling and high sink temperatures three components such as liquid vapour heat exchanger, solution heat exchanger and rectifier is used. Sankar et al.[9] integrated two advantages such as cooling and power from one system by combining refrigeration cycle and power generation cycle from solar energy. This can be done by dividing absorber into two streams. Tyagi [10] has used ammonia salts binary mixtures as refrigerant and compared the performance and pumping factor results given that binary mixture have a great potential than the normal refrigerants. Some researchers made some attempts to introduce solar water heaters. Makena harish et al. [11] designed eco-friendly vapour absorption system for heat water by using $\mathrm{Li}-\mathrm{Br}$ and water with the capacity of $5.25 \mathrm{KW}$ and calculated COP and tested under different operating conditions using hot water. Dilip kumar Mohnati et al[12] analyze the thermodynamic performance with respect to COP of solar vapour absorption refrigeration system. The design is based on different climatic conditions and is optimum use of solar energy.

2.1 Vapour cycle refrigeration can be classified as:

1. Vapour compression refrigeration

2. Vapour absorption refrigeration

In present investigation vapour absorption system is adopted and three fluids used in the refrigeration system:

1. Water
2. Hydrogen
3. Ammonia

\section{SOLAR COLLECTOR}

The amount of solar energy reaching the surface of the planet is so vast that in one year it is about twice as much as will ever be obtained from all of the Earth's non-renewable resources of coal, oil, natural gas, and mined uranium combined.

\section{A. Types of Solar Collectors}

Solar collectors are mainly divided in to two types they are: 1.Non concentrating or flat plate type solar collector. 2. Concentrating (focusing) type solar collector.

\section{B. Concentrating (Focusing) Type Solar Collector}

The term concentration ratio plays an important role in design of concentrating type solar collectors.

1) Concentration ratio

It is defined as the ratio of area of collecting

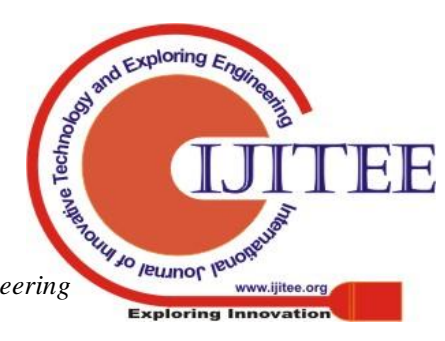


aperture in the area of the absorber.

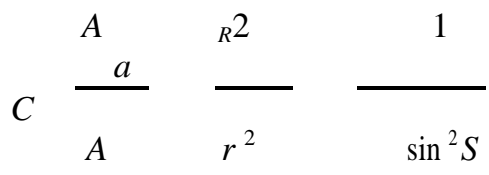

Where

C- Concentration Ratio Aa- Area of collecting aperture m2 Ar-Area of absorber, m2,

$\mathrm{R}$ - Distance from the sun to concentrator $\mathrm{m}$,

$r$ - Radius of the sun

$\theta$-half an angle subtended by sun.

Parabolic trough

This type of collector is generally used in solar power plants. A trough-shaped parabolic reflector is used to concentrate sunlight on an insulated tube (Dewar tube) or heat pipe, placed at the focal point, containing coolant which transfers heat from the collectors to the boilers in the power station. Alternatively the trough can be aligned on an east-west axis, this reduces the overall efficiency of the collector, due to cosine loss, but only requires the trough to be aligned with the change in seasons, avoiding the need for Tracking motors.

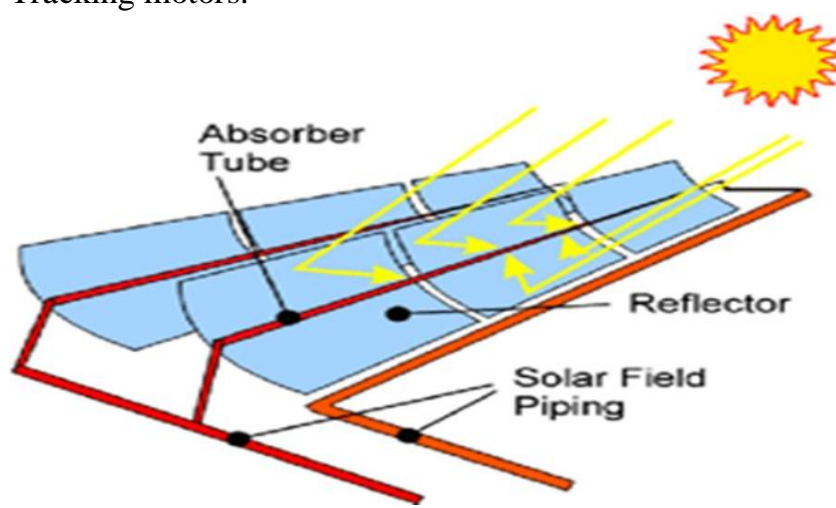

Fig. 1: The section of cusp

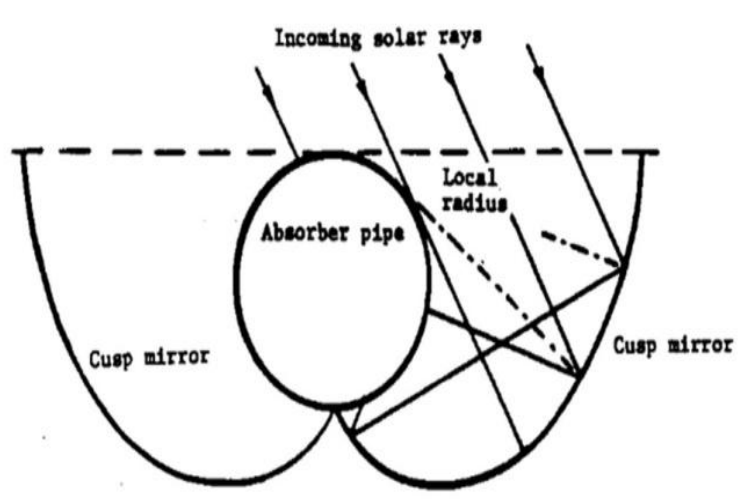

Fig. 2: The typical parabolic trough

\section{Two Dimensional In volute Cusps}

The peculiar advantage of in volute cusp in solar energy concentration had been recognized very early stages by Trombe and Meinel. Mathematically, the inbuilt of any curve is defined as a curve that intersects all its tangents at right angles. The Trombe Meinel designs a profile described by the locus of a string unwrapped from about a circular receiver.

Type of Concentrator : Cusp

Type of Focus : line

Lens or Mirror : mirror
Sun's Concentration: $1.5-2.5$

Tracking : No

Tracking Receiver : No

Temperature (C) : 121

Temperature (F) : 250

\section{DESIGN OF COLLECTORS}

\section{A. Design of Solar Collector}

Solar collector is the major part of the project which will collect the solar energy and send to the generator, design of solar collector starts from the power input to the generator of refrigeration system. The power required at the generator is $($ Pactual $)=80 \mathrm{~W}$. Taking the account of all the losses at boiler, tubes and heat exchange at the generator.

Preq $=$ Factor of safety $*$ Power required $=4 * 80=320 \mathrm{~W}$ (Factor of safety is assumed as 4) Solar irradiation at a tropical region $(\mathrm{I})=500 \mathrm{~W} / \mathrm{m} 2$ Effective area required to get desired power $=($ Preq $) / \mathrm{I}=320 / 500=0.64 \mathrm{~m} 2$.

\section{Reflectivity of aluminum foil is about 95 to 98}

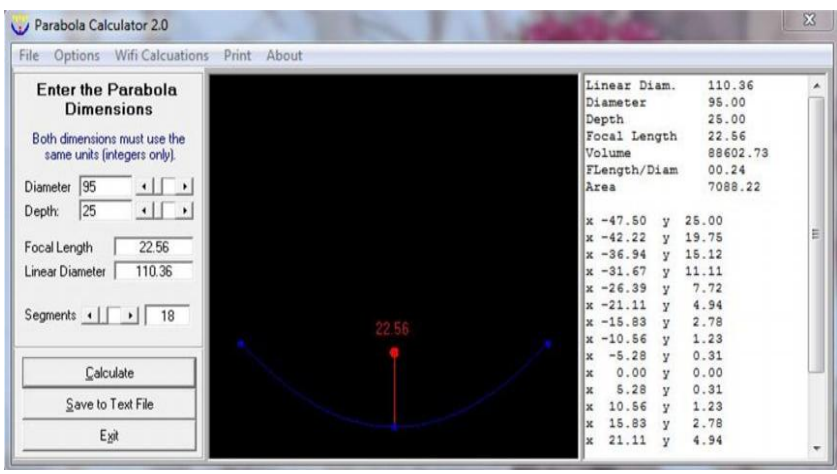

Fig. 3: Parabolic Calculator

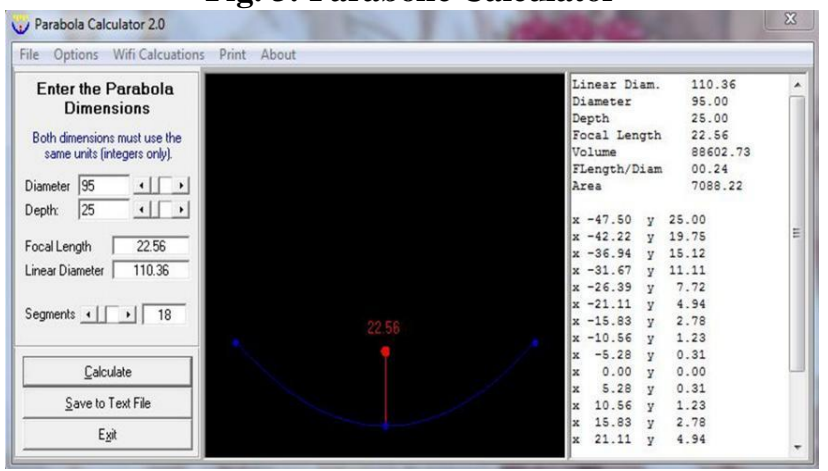

Fig. 4: parabolic Calculator Results

Taking reflectivity as $95=0.670 .7$ sq-mts. Diameter of solar collector $=0.9440 .95 \mathrm{~m}$ And we had taken the depth of the collector as $=0.25 \mathrm{~m}$ (Assumed) And using the parabola calculator focal point is calculated and found at a distance of $0.2256 \mathrm{~m}$ as shown in Figure 4.1

\section{B. Fabrication}

Fabrication of parabolic dish type solar collector with the parabolic dish type collector was made in order to collect the solar heat. The parabolic calculator as shown in Fig is used to obtain the various dimensions of the collector. The design of the collector was created the help of CAD software. 


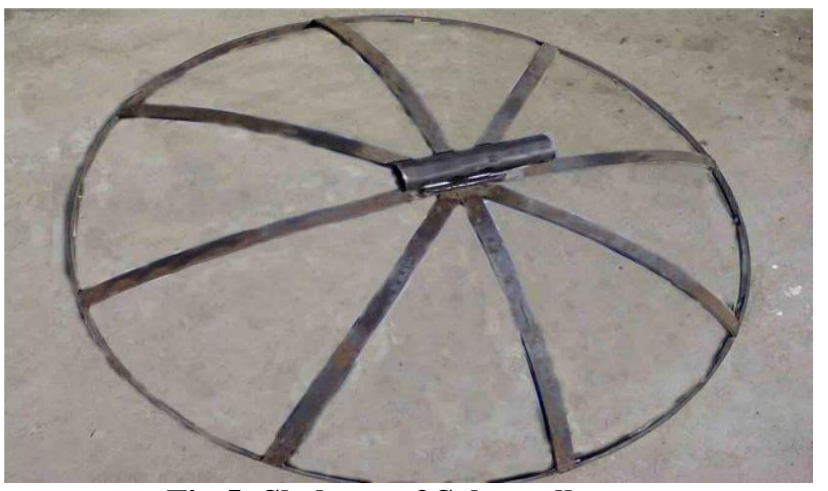

Fig.5: Skeleton of Solar collector

Firstly, we had taken the Mild Steel strips and bent them according to the shape of parabola drawn on the cardboard sheet with the thickness of $4 \mathrm{~mm}$. These strips are joined together by an arc welding process to form a parabolic dish as shown in the Fig 5. After making the skeleton of the collector .We had taken a roll of reflective material that is aluminum foil along with protective coating as shown in Fig 4.4. After marking the aluminum foil is cut into pieces by using the sheet metal cutting machine, fixed this process is repeated until all the strips are fixed to obtain the parabolic dish type collector as shown in Fig: 4.4

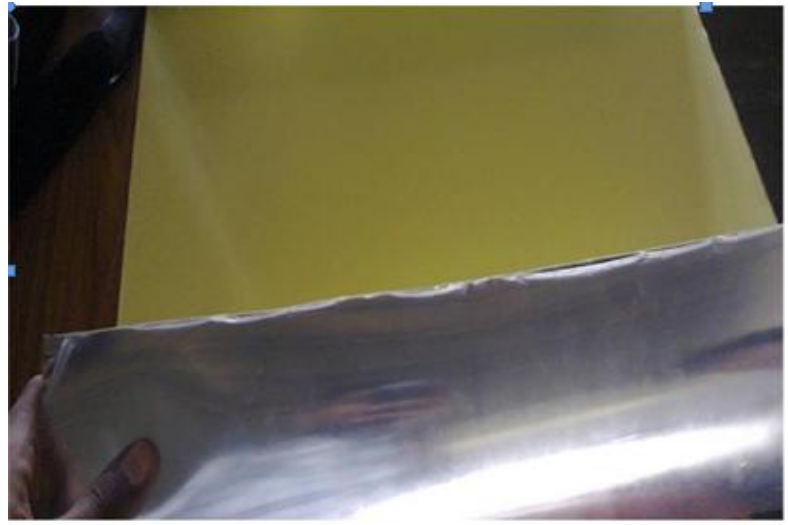

Fig.6: Aluminum foil

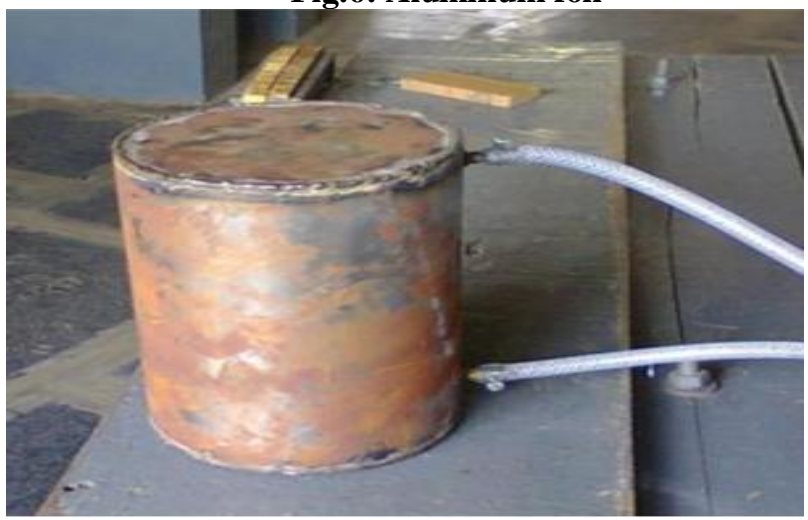

Fig. 7: Boiler

\section{Fabrication of boiler}

The boiler was made of GI iron sheet $(25 \times 20 \mathrm{cms})$ the sheet is bent into cylindrical shape by repeated hammer-ing. And the edges are joined by arc welding the top and bottom are also covered with the same GI sheet and leak proof joint was made by using an arc welding process. The provisions for water circulation (inlet and outlet) are made by using gas welding process as shown in Fig 4.5.

\section{Fabrication of vapor absorption unit}

- Tube in tube bending is the major part of the Solar Vapour absorption unit.

- Tube in tube bending can be done by using the general bending machine with a small technique.

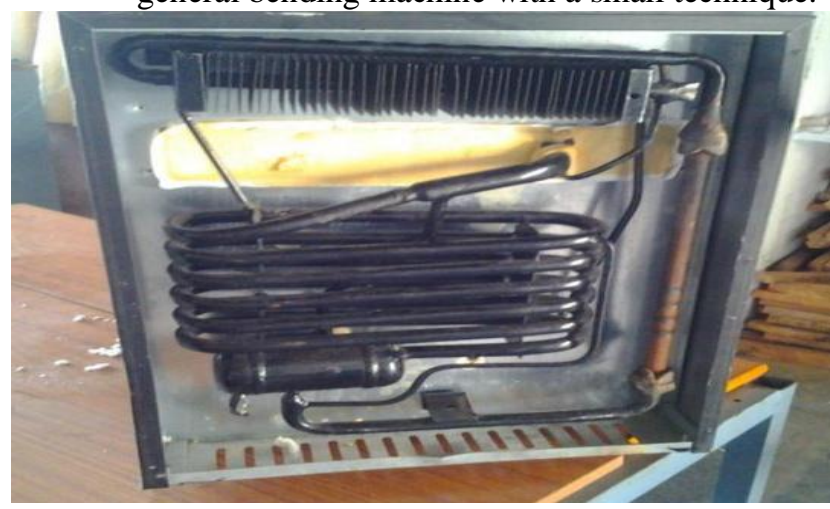

Fig. 8: Vapor Absorption Refrigeration Circuit

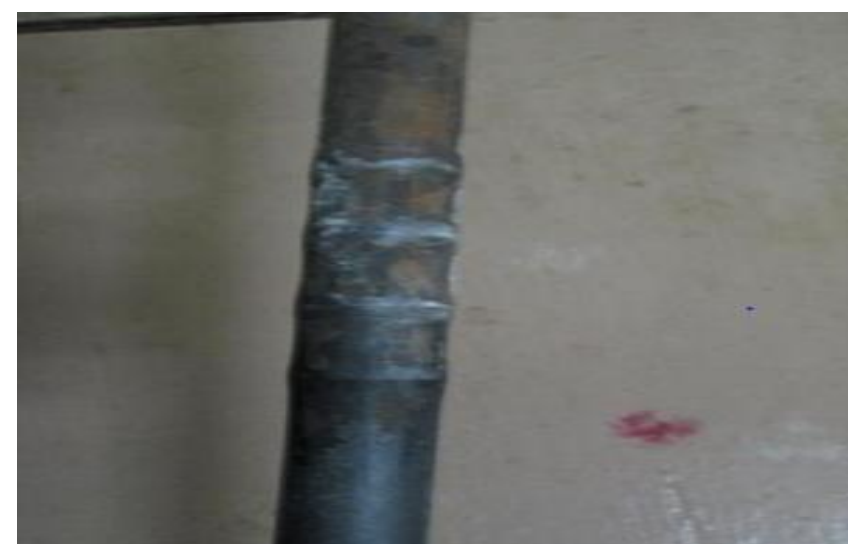

Fig. 9: Generator tube

E. The fabrication of vapor absorption system involves

1. Fabrication of generator

2. Fabrication of condenser

3. Fabrication of Evaporator

4. Fabrication of absorber

\section{F. Fabrication of generator}

The generator is a tube in tube component as shown in Fig: 4.7 The outer tube is made of mild steel and it is of diameter $15 \mathrm{~mm}$ and inner tube is also a mild steel tube of diameter $7 \mathrm{~mm}$. The tubes are placed one inside the other and tube in tube bending is carried out to obtain 90degrees bend.

\section{G. Fabrication of condenser}

The condenser is present next to the generator and it must be at a higher elevation than that of the generator. The Ammonia vapour from the generator will move upwards due to the force of buoyancy and condenses to liquid in the condenser. Rectangular fins (45 in number) are provided to the condenser to increase The fins are provided on the tube to increase heat dissipation and this tube connected to the generator by welding process the region of tube between condenser and generator acts as a rectifier.

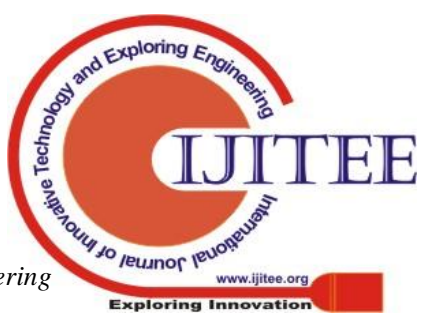




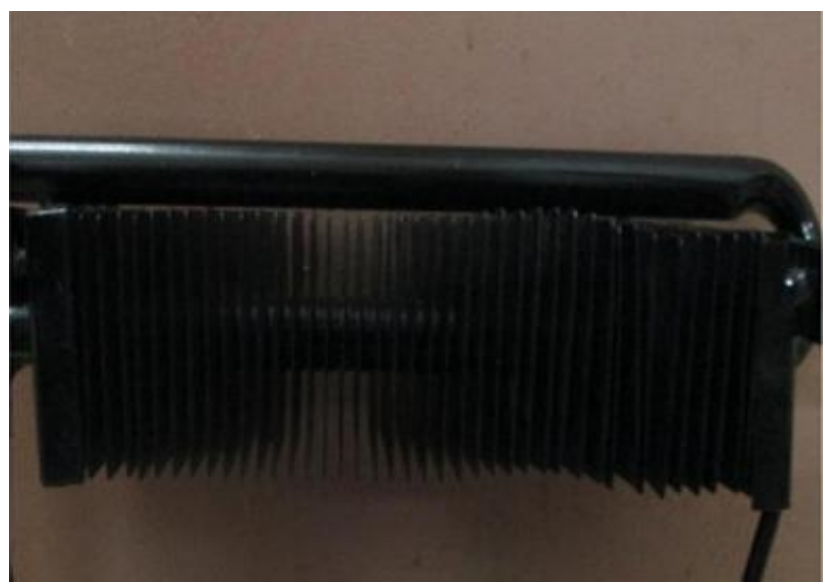

Fig. 10: Condenser with fins

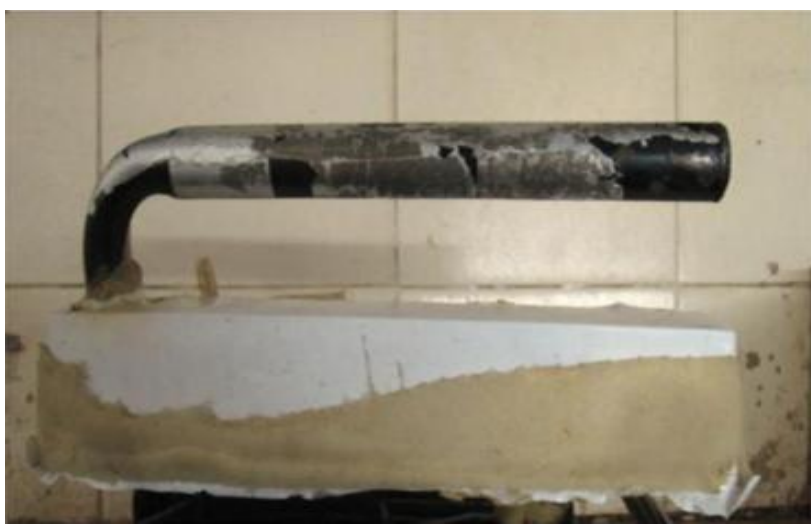

Fig. 11: Evaporator tube

\section{H. Fabrication of evaporator}

After condensation the ammonia liquid enters into the evaporator. It is a tube in tube structure made of MS. The inner tube of diameter $6 \mathrm{~mm}$ is placed in outer tube of diameter $22 \mathrm{~mm}$ and The MS tubes are bent as shown in Fig4.9

\section{Fabrication of Absorber}

The absorber is fabricated by MS tube of diameter $60 \mathrm{~mm}$ and length $10 \mathrm{cms}$ Holes are made by using drilling machine on the circumference to carry hydrogen gas to evaporator and to receive the hydrogen and ammonia vapour mixture from the evaporator. And the absorber is connected to the generator and evaporator by using MS tubes as shown in Figure 4.10. The ends of the absorber tubes are closed by MS caps of diameter $60 \mathrm{~mm}$.

\section{Charging}

Charging the system means filling the cooling system with refrigerant at appropriate concentration, pressure and quantity. In vapour absorption system, adequate amount of refrigerant must be charged. If the amount of refrigerant charged is too high, the desired cooling effect will not be obtained as there will not be adequate space for the evaporation of the refrigerant.

In our system, it contains three fluids. Hence charging the system is more complex compared to VAR system. Charging of each fluid is explained below.

\section{Ammonia}

Since ammonia vapor is toxic with irritating smell, it is desirable to charge aqua ammonia solution instead of charging the system with ammonia vapor. For this fresh water is taken with a bucket and ammonia vapour is allowed to pass through this water. Ammonia readily absorbs in water. It is kept as such until the solution becomes saturated. The solution begins to boil as the reaction is exothermic. Now this solution is poured into the generator tube through the coupling welded at the top of it. Three fourth of the generator tube is filled with aqua ammonia solution. Then the generator tube is closed with the end cap.

\section{Hydrogen}

Hydrogen is the carrier gas in the system. It helps to keep the pressure of the system constant. The system is pressurized only after charging of hydrogen. Hydrogen line is fixed at the absorber tank. There will a small pressure rise inside the system due to the liberation of ammonia vapour. This is because the system is charged with saturated am-ammonium hydroxide solution. A pressure equal to the vapour pressure of ammonia exists inside the system. If the hydrogen charging line is open, this pressurized ammonia will escape. In order to avoid this, the pressure inside the system must be reduced. For this the generator tube is covered with ice cubes. This ensures low pressure inside the system as more vapour ammonia gets dissolved into the solution. Now the level of the generator pipe is raised so that absorber tank is now fully filled with aqua ammonia solution. This is done to ensure non return of the hydrogen gas during charging.

Now by means of rubber tube, hydrogen cylinder is connected to the hydrogen charging line. By monitoring the pressure gauge fixed on the generator, adequate amount of hydrogen is charged to get the required system pressure. After charging, the valve is closed and ice cube is removed after the fabrication and charging the vapour absorption unit is fixed to the closed cabin to act as a refrigerator

\section{ANALYSIS}

Table 1: Experimental Results during day 1

\begin{tabular}{|c|c|c|c|c|}
\hline Time & $\begin{array}{l}\text { Duration } \\
\text { in Hours }\end{array}$ & $\begin{array}{c}\text { Room } \\
\text { temperat } \\
\text { ure Tc } \\
\circ \mathrm{C}\end{array}$ & \begin{tabular}{|c|} 
Genrator \\
Temperatu \\
re TG \\
oc
\end{tabular} & $\begin{array}{c}\text { Evaporator } \\
\text { temperature Tc } \\
\text { oC }\end{array}$ \\
\hline $\begin{array}{l}9.00 \\
\text { A.M }\end{array}$ & 0 & 30 & 30 & 30 \\
\hline $\begin{array}{c}10.00 \\
\text { A.M }\end{array}$ & 1 & 30 & 70 & 30 \\
\hline $\begin{array}{c}11.00 \\
\text { A.M }\end{array}$ & 2 & 31 & 80 & 29 \\
\hline $\begin{array}{c}12.00 \\
\text { A.M }\end{array}$ & 3 & 31 & 85 & 26 \\
\hline $\begin{array}{l}1.00 \\
\text { P.M }\end{array}$ & 4 & 32 & 90 & 23 \\
\hline $\begin{array}{l}2.00 \\
\text { P.M }\end{array}$ & 5 & 32 & 92 & 23 \\
\hline $\begin{array}{l}3.00 \\
\text { P.M }\end{array}$ & 6 & 32 & 92 & 24 \\
\hline $\begin{array}{l}4.00 \\
\text { P.M }\end{array}$ & 7 & 32 & 90 & 28 \\
\hline $\begin{array}{l}5.00 \\
\text { P.M }\end{array}$ & 8 & 30 & 85 & 28 \\
\hline
\end{tabular}

The unit is kept under the sun on 14th and 15th of march 2013 and readings of Generator, condenser and evaporator temperatures are taken for each an hour to find the minimum evaporator temperature and C.O.P is calculated at the mini-mum evaporator temperature by using the following formula.

Coefficient of Performance (C.O.P) of the system is given by 


$$
\text { (C.O.P) } \left.\max =\left(\frac{T)_{;} \star T(C)}{T_{G}}\right) \quad \frac{T_{E}}{T_{C}-T_{E}}\right)
$$

Where,

$\mathrm{TE}=$ Temperature of the evaporator, $\mathrm{TC}=$ Temperature of the condenser, $\mathrm{TG}=$ Temperature of the generator.

$$
\begin{aligned}
(\text { C.O.P })_{\max } & =\left(\frac{T_{G}-T_{G}}{T_{G}}\right) *\left(\frac{T_{E}}{T_{C}-T_{E}}\right) \\
& =\left(\frac{92-32}{92}\right) \times\left(\frac{23}{32-23}\right) \\
& \approx 1.6
\end{aligned}
$$

Table 2: Experimental results during day 2

\begin{tabular}{|l|c|c|l|l|}
\hline Time & Duration & $\begin{array}{l}\text { Room } \\
\text { temperature } \\
\mathrm{TC}^{\circ} \mathrm{C}\end{array}$ & $\begin{array}{l}\text { Genrator } \\
\text { Temperature } \mathrm{T}_{\mathrm{G}}\end{array}$ & $\begin{array}{l}\text { Evaporator } \\
\text { temperature } \mathrm{TE}\end{array}$ \\
\hline $9.00 \mathrm{~A} . \mathrm{M}$ & 0 & 29 & 29 & 29 \\
\hline 10.00 A.M & 1 & 30 & 70 & 30 \\
\hline 11.00 A.M & 2 & 31 & 77 & 29 \\
\hline 12.00 A.M & 3 & 31 & 82 & 27 \\
\hline 1.00 P.M & 4 & 32 & 91 & 25 \\
\hline 2.00 P.M & 5 & 33 & 92 & 23 \\
\hline 3.00 P.M & 6 & 32 & 92 & 23 \\
\hline 4.00 P.M & 7 & 31 & 90 & 28 \\
\hline 5.00 P.M & 8 & 31 & 85 & 29 \\
\hline
\end{tabular}

$$
\begin{aligned}
(\text { C.O.P })_{\max } & \left.\left.\stackrel{T_{G}-T_{C}}{T_{G}}\right)\right) *\left(\frac{T_{E}}{T_{C}-T_{E}}\right) \\
& =\left(\frac{92-33}{92}\right) *\left(\frac{23}{33-23}\right)
\end{aligned}
$$

$\approx 1.4 \overline{75}$

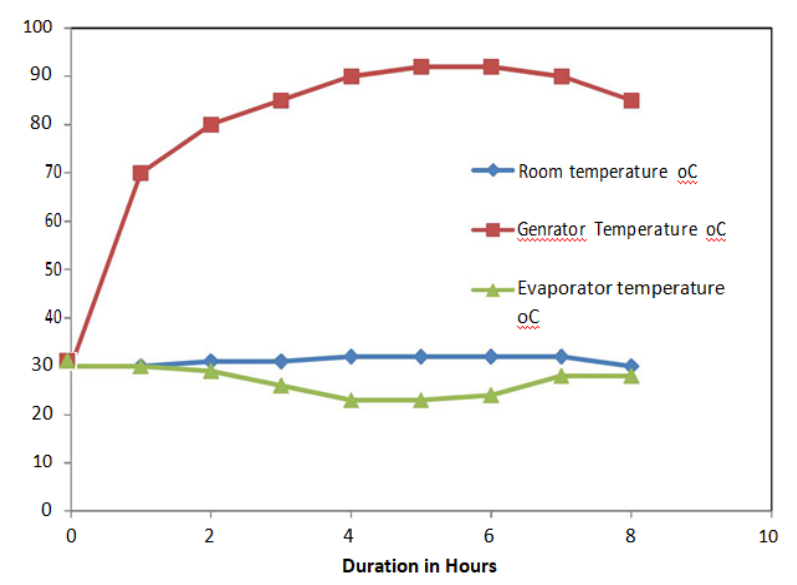

(a)

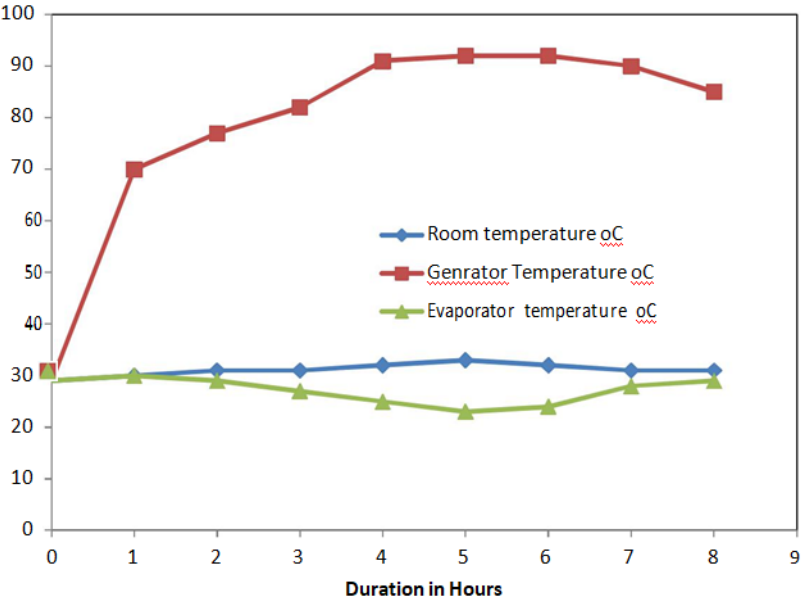

(b)

Fig. 12: Temperature Vs Time Plot for (a) Day 1, (a) Day 2

C.O.P of the system is measured at the minimum evaporator temperature because C.O.P has to be measured only in the steady state of the system, This is due to maximum solar energy is available at the 12 to 2 P.M only, later it decreases. The C.O.P of the unit is calculated at the mid-day i.e. after 6hrs from the starting of the experiment. From the temperature Vs duration plot, it is clear that the maximum solar energy is available at midday, boiler is able to rise a temperature of around $92 \mathrm{OC}$ and similarly the evaporator is able to maintain minimum temperature of 230C. It can be seen from the Tables 5.1 and 5.2 that the generator temperature and evaporator temperature are proportional to each other. As all the conditions are similar in nature, the variations in temperature graphs of the day 1 and day 2 are very minute. This represents the consistency of present system.

\section{CONCLUSION}

This project was to build a domestic refrigerator with zero running cost. Experimental results states that the cooling of the cabin is proportional to the outside temperature, which gives high cooling at midday and moderate at other times. This unit had attained a minimum temperature of $230 \mathrm{C}$ at around 1:00P.M. on 14th and 15th march 2013 with a C.O.P of 1.6 As the project utilizes solar power as the input, It can be employed with minimum maintenance throughout the year. If people use the Vapour absorption refrigeration system along with Vapour compression refrigeration system, It can reduce the power consumption during day times and the same combination can be used at night times by the power. By connecting this Solar vapour refrigeration system to large size shopping malls, one can have a centralized Air conditioning in the day times the electrical consumption can be greatly reduced. By using the Concentrated solar power one can utilize the Solar energy to a maximum extent, Research is going on to utilize the heat energy from the concentrated solar power to produce the steam and generate power i.e., It serves a direct replacement or the boiler in Thermal power plants.

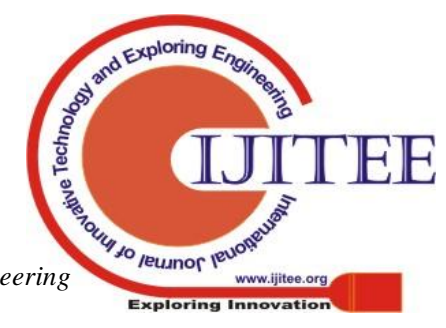




\section{FUTURE SCOPE}

This system can Analyzed by using various materials for the solar reflector and various shapes of solar collector like involutes and double involutes shape. Rate of cooling of the system can be increased by providing the surface contact of the heat exchanger rather than using the line contact. Further investigations can be made to improve the C.O.P of the system

\section{REFERENCES}

1. Celina Maria Cunha Ribeiro, Evânia Celeste da Costa Moreira, Carlos Antonio Cabral dos Santos, Wilson Luciano de Souza, Rodrigode Almeida Leal. Study of a diffusion-absorption refrigeration cycle using ammonia-water-heliumas working fluids, 18th International Congress of Mechanical Engineering November 6-11, 2005

2. Velmurugan V, RajaBalayanan S.R, Surendhra Babu K and Sakthivadivel D, Investigation of a novel solar powered absorption refrigeration system with solar point collector, Research Journal of Chemical Sciences Vol. 1(7), Oct. 2011,p. 51-56

3. Joshua FOLARANMI Leonardo, Design Construction and Testing of a Parabolic Solar Steam Generator, Electronic Journal of Practices and Technologies ISSN 1583-1078 Issue 14, January-June 2009, p. 115-133.

4. Ali benhmidene, bechir chaouachi, mahmoud bourouis, and slimane gabsi, Effect of operating conditions on the performance of the bubble pump of absorption diffusion refrigeration cycles, Thermalscience, year 2011, vol.15, no.3, pp.793806

5. V Mittal, K S Kasana, N S Thakur, Modeling and simulation of a solar absorption cooling system for India,Journal of Energy in Southern Africa, Vol 17, No 3, August 2006

6. S. Gabsi ,B. Chaouachi, Design and simulation of an absorption diffusion solar refrigeration unit, American Journal of Applied Sciences, FEB, 2007

7. Ali Benhmidene, Bechir Chaouachi, Slimane Gabsi, Mahmoud Bourouis, Modeling of heat flux received by a bubble pump of absorption-diffusion refrigeration cycles, Heat Mass Transfer (2011) 47:1341-1347, DOI10.1007/s00

8. Subhadip Roy, M. P. Maiya," Analysis of R134a-DMAC vapour absorption refrigeration system with add on components",IJTS1(1):26-35,june 2012.

9. R. Sankar, T srinivas," Solar thermalbased power and vapour absorption refrigeration system",proceedia engineering,38,730-736,2012.

10. K. P. Tyagi ," Ammonia -salts vapour absorption refrigeration systems", Jounal of heat recovery systems, 4(6),427-431,2013.

11. Makena Harish, Reddy ANR,'Design of solar based vapour absorption system", DOI:10.13140/RG.2.1.3284.7120/1ISBN: 978-93-83038-28-2,ICEMS, Pg No: 104-110-2014.

12. Dilip kumar Mohanty, Abhijit padiary," Thermodynamic performance analysis of a solar vapour absorption refrioration system", IJERSTE, ISSN:2319-7463,4(4),45-54,April 2015. 